\title{
Parametric study on effect of pinch and approach points on heat recovery steam generator performance at a district cooling system
}

\author{
Adzuieen Nordin and Mohd Amin Abd Majid \\ ${ }^{1}$ Department of Mechanical Engineering, Universiti Teknologi Petronas, \\ Bandar Seri Iskandar, \\ 31750 Tronoh, Perak, Malaysia \\ *Email: mamin_amajid@utp.edu.my \\ Phone: +605368 8000; Fax: +605368 8151
}

\begin{abstract}
Heat recovery steam generators are important equipment in district cooling plants. The capability of heat recovery steam generators in generating steam influences the steam absorption chiller's performance. The steam generation capability of the heat recovery steam generators in turn is linked to the values of pinch point and approach point. Hence, a study on the pinch point and approach point for the heat recovery steam generators would be useful in understanding the effects of varying pinch point and approach point values to the heat recovery steam generators performance. In relation to this subject, a parametric study on the heat recovery steam generators has been done. The study covered the effects of the pinch point and approach point on the following: mass flow rate of steam generated, exhaust heat temperature leaving the heat recovery steam generators, and the efficiencies of the heat recovery steam generators. The first law of thermodynamics was used for the analysis. Four scenarios were covered in the study: the effect of the pinch point and approach point on steam generation, the effect of the pinch point and approach point on the exhaust heat temperature leaving heat recovery steam generators, effect of the pinch point and approach point on the efficiency of heat recovery steam generators, and the effect of the exhaust heat temperature of the gas turbine on the mass flow rate of steam. Operating data at the Universiti Teknologi PETRONAS gas district cooling plant were used to validate the model. The results from the first scenario indicated that higher pinch point and approach point led to a decrease in the steam being generated. For the second scenario, the increase in pinch point and approach point resulted in higher exhaust heat temperature leaving the heat recovery steam generators. Meanwhile, for the third scenario, it was noted that there was only a minimal variation of efficiency of the heat recovery steam generator when the pinch point and approach point were increased. The findings of the fourth scenario indicated that with higher gas turbine exhaust heat temperatures, there was an increase in steam being generated. Therefore, the findings could be useful for the plant to set the operating parameters for operating heat recovery steam generators.
\end{abstract}

Keywords: Approach point; efficiency; heat recovery steam generator; pinch point.

\section{INTRODUCTION}

Heat Recovery Steam Generator (HRSG) is normally installed in district cooling plants. At the district cooling plant, the HRSG is coupled with an absorption chiller to generate 
chilled water for cooling purposes. The HRSG generates steam using Gas Turbine (GT) exhaust heat. The steam is used by Steam Absorption Chiller (SAC) to generate chilled water. Performance of HRSG affects the overall performance of the district cooling plant [1]. Many studies on the performance of HRSG have been undertaken [2]. Hongcung et al. [3] demonstrated a comprehensive algorithm modeling of a multi-pressure HRSG based on the heat exchangers layout. They developed a general model and analysed the thermodynamic performance of three different heat exchangers layouts to find the mass flow rates of steam and heat efficiency. Hussam and Alexander [4] proposed a split concept for boilers and HRSGs to reduce the heat exchange area and the requirement of power recycled. Mahmoud and Adel [5] analysed a thermodynamic comparison of HRSG exhaust gas temperatures between $350^{\circ} \mathrm{C}$ to $650^{\circ} \mathrm{C}$. The authors noted that the optimal pressures were achieved by increasing the pressure level. Increasing pressure level also led to the decreased value of pinch point (PP). Tyagi and Khan [6] investigated the effect of turbine exhaust temperature, stack temperature and ambient temperature on the efficiency of combined cycle plant and concluded that the stack temperature was the most dominating factor that contributed to increasing the efficiency of the combined cycle plant. Using a numerical approach, reference [7] reported that the following factors affected the performance of the HRSG: mass flow rate of exhaust heat and steam, temperature of exhaust heat and steam, pressure and the compositions of gas and water used in the HRSG, water and air temperature, the geometry of the HRSG, and the fluctuating of the GT conditions.

In order to determine the performance of HRSG, thermodynamic analysis has to be carried out. Butcher and Reddy [8] studied the performance of a waste heat recovery power generation system based on temperature profiles across HRSG, network output, second law efficiency and entropy generation. The effect of PP on the performance of HRSG was also investigated. The authors reported that when the PP increased, the steam generated from HRSG decreased due to reduced heat transfer in HRSG. However, when the waste heat temperature from the GT increased, the steam generation rate increased due to more energy input to the HRSG. The variation of PP for the case of first law efficiency was not so much compared to the second law efficiency. Normally, HRSG is designed for a set of conditions. Unfortunately, in the real situation, HRSG is operated in different parameters due to plant constraints such as steam demand and different ambient conditions which can affect the entire plant performance. Ganapathy [9] reported the performance of HRSG based on the capability of steam generated which was affected by the conditions of exhaust heat from GT. There are two variables that directly affect steam and gas temperature profiles, namely PP and AP. It is desirable to have the best range of PP that increases the mass flow rate of steam. The PP and AP are thus important parameters that influence the HRSG performance. This study was carried out to investigate these factors on the operating HRSG available at a district cooling plant.

\section{METHODS AND MATERIALS}

In the present work, an HRSG equipped with an economiser and evaporator was considered. The HRSG was an unfired type. Performance of HRSG was evaluated based on the mass flow rate of steam generated and the efficiency of HRSG. The mass flow rate of steam generated by HRSG could be evaluated if the PP and AP were known. PP and AP were important parameters which influenced the temperatures within the economiser and evaporator. The related temperatures are shown in Figure 1. 


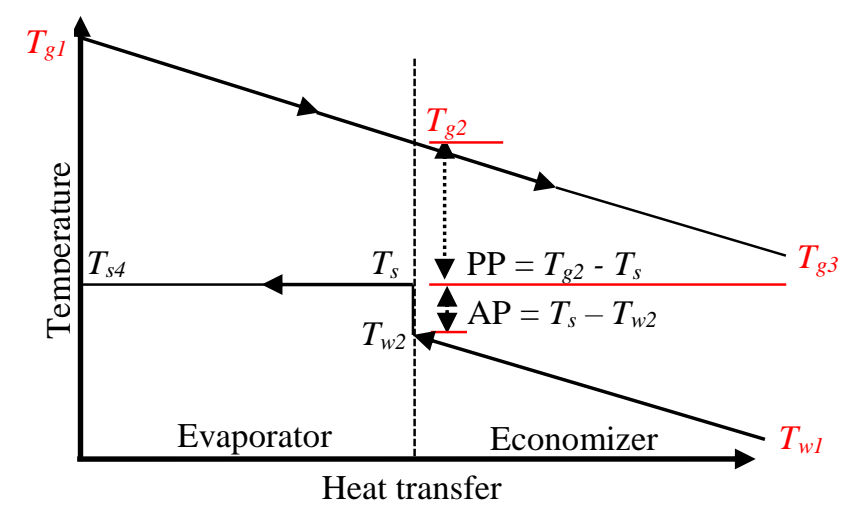

Figure 1. Typical temperature profiles for a single pressure HRSG.

Figure 1 shows the typical gas and steam temperature profiles in a HRSG consisting of an evaporator and economiser operating at a single pressure. The exhaust heat enters the evaporator at $T_{g 1}$ and flows through the evaporator and economiser and is discharged from HRSG into the environment at $T_{g 3}$. Water enters the economiser at temperature $T_{w 1}$ and is sensibly heated at $T_{w 2}$, after which it enters the evaporator. The water boils in the evaporator at the saturation temperature $T_{s}$ and leaves the evaporator as saturated steam at $T_{s 4}$. The steam is then delivered to SAC to generate chilled water.

Equation (1) and Eq. (2) show the relationship of PP and AP to $T_{g 2}, T_{s}$ and $T_{w 2}$. By knowing the PP, AP and $T_{s}$, the value of $T_{g 2}$ and $T_{w 2}$ could be obtained. The value of $T_{g 2}$ and $T_{w 2}$ were then used in Eq. (4) and Eq. (6).

$$
\begin{aligned}
& \mathrm{PP}=T_{g 2}-T_{s} \\
& \mathrm{AP}=T_{s}-T_{w 2}
\end{aligned}
$$

\section{Mass Flow Rate Of Steam Generated}

Equation (3) was used to calculate the mass flow rate of steam generated [9].

Mass flow rate of steam generated

$$
=\frac{\text { Evaporator duty }}{\text { Enthalpy absorbed by steam in evaporator }}
$$

Evaporator duty was required to be calculated in order to evaluate the mass flow rate of steam generated. The evaporator duty was calculated using Eq. (4);

$$
\begin{aligned}
& \text { Evaporator duty } \\
& \qquad=\dot{m}_{\text {exhaust gas }} \times(1-h l) \times C p_{g(\text { evap }) @ T g 1} \times\left(T_{g 1}-T_{g 2}\right)
\end{aligned}
$$

where $\dot{m}_{\text {exhaust gas }}$ is the mass flow rate of exhaust heat from GT, $h l$ is the percentage of heat loss, $T_{g 1}$ is the exhaust heat from GT, and $T_{g 2}$ is the temperature of exhaust heat entering economiser. $C p_{g(\text { evap })}$ is the specific heat gas of evaporator and was calculated as [10]; 


$$
\begin{gathered}
C p_{g}=0.991615+\left(6.99703 \times 10^{-5} \times T\right)+\left(2.7129 \times 10^{-7} \times T^{2}\right) \\
-\left(1.22442 \times 10^{-10} \times T^{3}\right.
\end{gathered}
$$

Eq. (6) was used to evaluate enthalpy absorbed by steam in evaporator [9];

Enthalpy absorbed by steam in evaporator $=$

$$
\left(h_{s}-h_{w @ T w 2(\text { fluid })}+b l \times\left(h_{w @ T w 2(\text { vapor })}-h_{w @ T w 2(\text { fluid })}\right)\right)
$$

where $b l$ is the blow down factor and $h_{s}, h_{w @ T w 2 \text { (fluid) }}$ and $h_{w @ T w 2 \text { (vapor) }}$ are the enthalpy of steam, saturated water entering evaporator, and saturated water in vapor state, respectively.

\section{Gas Temperature Leaving HRSG}

For the evaluation of gas temperature leaving HRSG, Eq. (7) was used [9];

$$
T_{g 3}=T_{g 2}-\text { Gas temperature drop }
$$

where the $T_{g 2}$ was obtained from Eq. (1). The temperature drop was expressed as [9];

$$
\begin{gathered}
\text { Gas temperature drop }=\frac{\text { Economiser duty }}{\left(\dot{m}_{\text {exhaust gas }} \times C p_{g(\text { econ })} \times(1-h l)\right)} \\
\text { Economiser duty }=\dot{m}_{\text {steam }} \times(1+b l) \times\left(h_{w @ T w 2(\text { fluid })}-h_{w @ T w 1}\right)
\end{gathered}
$$

where $\dot{m}_{\text {steam }}$ is the mass flow rate of steam obtained from Eq. (3), $h_{w @ T w 2 \text { (fluid) }}$ is the enthalpy of saturated water entering evaporator and $h_{w @ T w 1}$ is the enthalpy of feed water.

\section{Performance of HRSG}

HRSG efficiency is also an important factor which influences the efficiency of district cooling plant. Using mass and energy balance equations, Eq. (10) was used to evaluate the efficiency of the HRSG [9];

$$
\eta_{\text {HRSG }}=\frac{\text { Energy given to steam }}{(\text { gas flow } \times \text { inlet enthalpy })+\text { fuel input on LHV basis }}
$$

Substituting the parameters Eq. (10) becomes;

$$
\eta_{\mathrm{HRSG}}=\frac{\dot{m}_{\text {steam }}\left(h_{\text {steam }}-h_{w @ T w 1}\right)}{\left(\dot{m}_{\text {exhaust gas }} C p_{g}\left(T_{g 1}-T_{g 3}\right)\right)+\left(\dot{m}_{\text {fuel }} \times L H V\right)}
$$

where $\dot{m}_{f u e l}$ is the mass flow rate of fuel and $L H V$ is the Low Heating Value of the GT fuel.

In this study, the mass flow rate of steam, the temperature of exhaust gas leaving HRSG, and the efficiency of HRSG were determined by varying the values of PP and AP. The results were used to determine the values of PP and AP that generated the maximum steam rate, the lowest temperature of exhaust heat leaving HRSG, and the highest efficiency of HRSG.

\section{Case Study}


HRSG at Universiti Teknologi Petronas (UTP) was taken as a case study as shown in Figure 2. The HRSG capacity is 12 tons/hr. The HRSG is normally operated from 7 a.m to 11.00 p.m daily using exhaust gas from the GT at the plant. In this study, it was assumed $66.6 \%$ of the exhaust gas was captured by the HRSG. This was based from the study by M. Amin et al. [11]. The HRSG generated steam which was used to produce chilled water by the absorption process. The chilled water is used for meeting the cooling demand of UTP campus as well as the plant. The following assumptions were used for the analysis $[8]$;

(i) System is at a steady state.

(ii) No pressure drops on the steam side.

(iii) Pressure drop on the gas side does not affect its temperature.

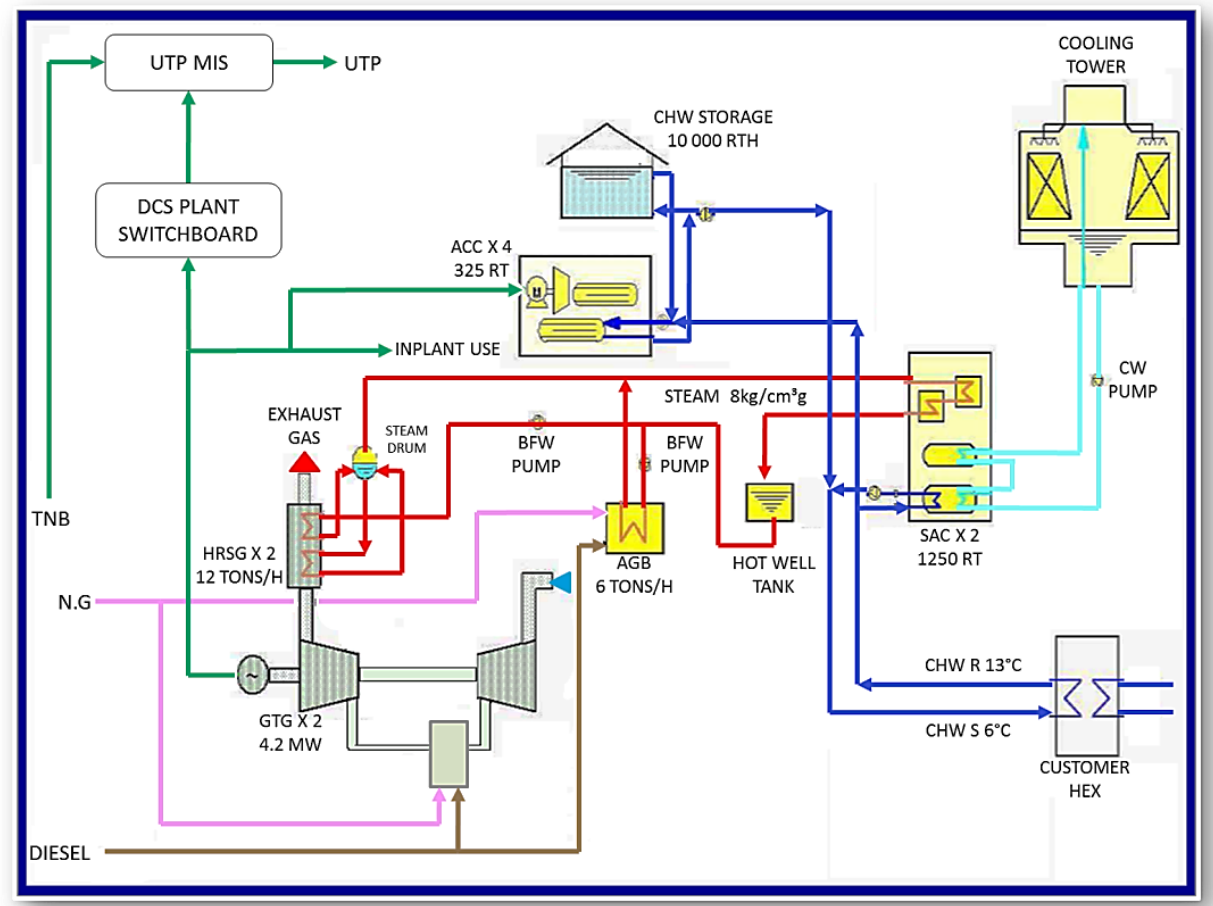

Figure 2. Universiti Teknologi Petronas District Cooling System [12].

Parameters in Table 1 were used to determine the temperature profile of the HRSG.

Table 1. UTP HRSG parameters [13].

\begin{tabular}{llc}
\hline Parameters & & Value \\
\hline Mass flow rate of exhaust gas & $(\mathrm{kg} / \mathrm{s})$ & 19.30 \\
Exhaust gas inlet temperature & $(\mathrm{K})$ & 648 \\
Steam pressure & $(\mathrm{bar})$ & 8.69 \\
Steam temperature & $(\mathrm{K})$ & 453 \\
Feed water temperature & $(\mathrm{K})$ & 355.7 \\
Blowdown factor & - & 0.05 \\
Heat loss factor & $(\%)$ & 2 \\
\hline
\end{tabular}




\section{RESULTS AND DISCUSSION}

\section{Effect of PP and AP on Steam Generation}

The plot of PP and AP on steam generation is shown in Figure 3. The plot was based on $70 \%, 50 \%$ and $30 \%$ of exhaust gas diverted to HRSG. For the case of varying PP, the value of AP was maintained at $15 \mathrm{~K}$. Meanwhile, for the case of varying AP values, the value of PP was maintained at $20 \mathrm{~K}$. As PP and AP increased, the mass flow rate of steam decreased. The same results were noted throughout all cases. This indicated that high PP and AP values resulted in lower steam being generated. The reason being, higher PP and AP led to the increase of exhaust gas temperature entering the economiser in HRSG. This led to the reduction of heat transfer in the evaporator and hence a lower rate of steam being produced [14].

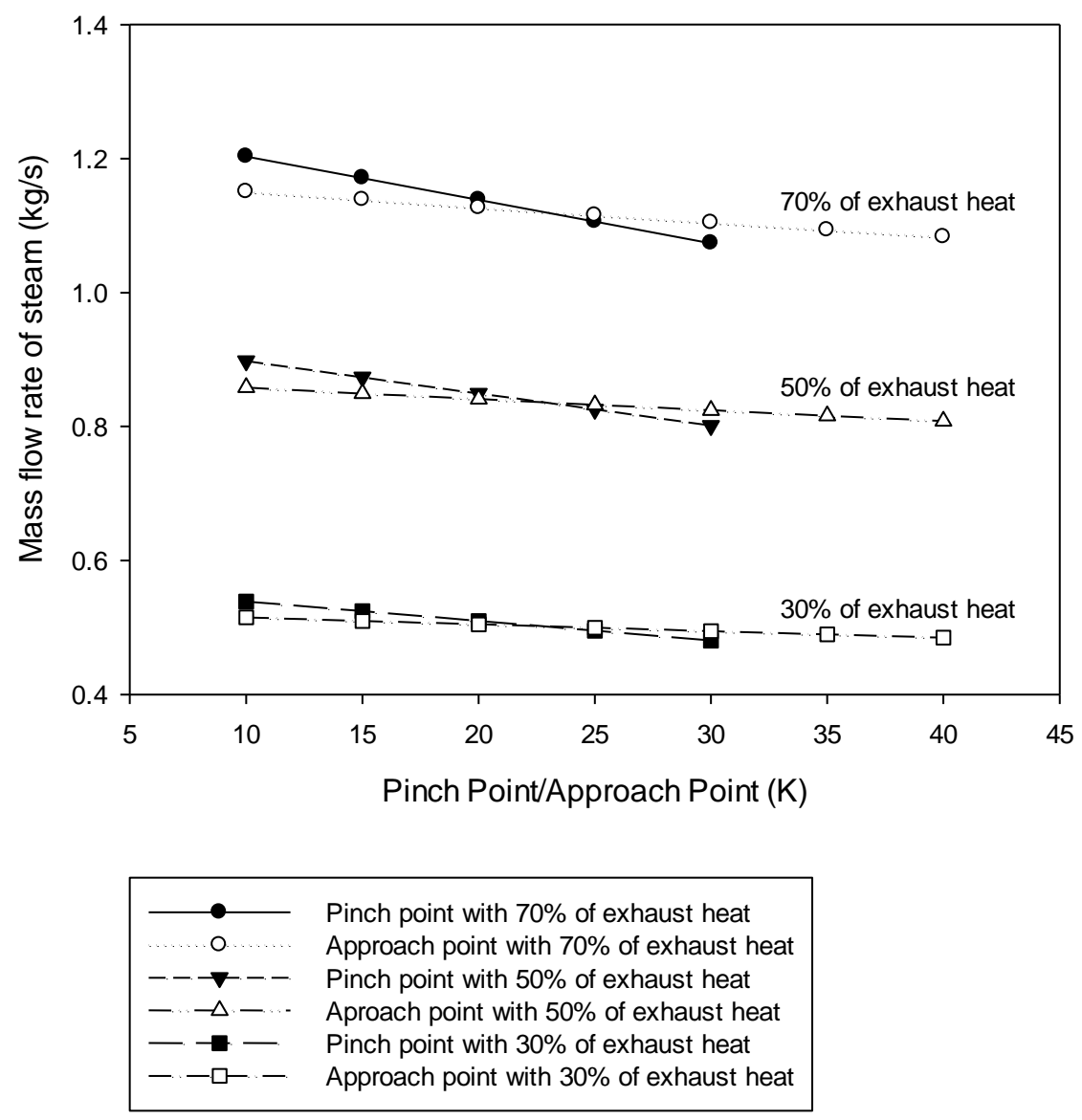

Figure 3. Effect of PP and AP of HRSG on mass flow rates of steam.

The summary of results for PP and AP are tabulated in Tables 2 and 3, respectively. Table 2 indicates the decreasing steam generated with increasing PP with AP maintained at $15 \mathrm{~K}$. Table 3 shows the decreasing steam generated with increasing AP while PP was maintained at $20 \mathrm{~K}$. 
Parametric study on effect of pinch and approach points on heat recovery steam generator performance at a district cooling system

Table 2. Mass low rate of steam with PP varying from $10 \mathrm{~K}$ to $30 \mathrm{~K}$ with AP at $15 \mathrm{~K}$.

\begin{tabular}{|c|c|c|c|c|}
\hline \multirow[b]{2}{*}{$\mathrm{AP}(\mathrm{K})$} & \multirow[b]{2}{*}{$\mathrm{PP}(\mathrm{K})$} & \multicolumn{3}{|c|}{ Mass flow rate of steam $(\mathrm{kg} / \mathrm{s})$} \\
\hline & & $\begin{array}{c}70 \% \text { of exhaust } \\
\text { heat }\end{array}$ & $\begin{array}{l}50 \% \text { of exhaust } \\
\text { heat }\end{array}$ & $\begin{array}{c}30 \% \text { of exhaust } \\
\text { heat }\end{array}$ \\
\hline \multirow{5}{*}{15} & 10 & 1.20 & 0.90 & 0.54 \\
\hline & 15 & 1.17 & 0.87 & 0.52 \\
\hline & 20 & 1.14 & 0.85 & 0.51 \\
\hline & 25 & 1.11 & 0.83 & 0.50 \\
\hline & 30 & 1.07 & 0.80 & 0.48 \\
\hline
\end{tabular}

Table 3. Mass flow rate of steam with AP varying from $10 \mathrm{~K}$ to $40 \mathrm{~K}$ with $\mathrm{PP}$ at $20 \mathrm{~K}$.

\begin{tabular}{|c|c|c|c|c|}
\hline \multirow[b]{2}{*}{$\mathrm{PP}(\mathrm{K})$} & \multirow[b]{2}{*}{$\mathrm{AP}(\mathrm{K})$} & \multicolumn{3}{|c|}{ Mass flow rate of steam $(\mathrm{kg} / \mathrm{s})$} \\
\hline & & $\begin{array}{c}70 \% \text { of exhaust } \\
\text { heat }\end{array}$ & $\begin{array}{c}50 \% \text { of exhaust } \\
\text { heat }\end{array}$ & $\begin{array}{c}30 \% \text { of exhaust } \\
\text { heat }\end{array}$ \\
\hline \multirow{7}{*}{20} & 10 & 1.15 & 0.86 & 0.52 \\
\hline & 15 & 1.14 & 0.85 & 0.51 \\
\hline & 20 & 1.13 & 0.84 & 0.50 \\
\hline & 25 & 1.12 & 0.83 & 0.50 \\
\hline & 30 & 1.10 & 0.82 & 0.49 \\
\hline & 35 & 1.09 & 0.82 & 0.49 \\
\hline & 40 & 1.08 & 0.81 & 0.48 \\
\hline
\end{tabular}

\section{Effect of PP and AP on Exhaust Heat Temperature Leaving HRSG}

Figure 4 presents the effect of PP and AP on exhaust heat temperature leaving the HRSG in three different mass flow rates of exhaust heat entering the HRSG. Equation (7) was used for evaluating the temperature of exhaust heat leaving the HRSG. This could be explained by the fact that the amount of gas temperatures that dropped in the HRSG was constant, which led to higher exhaust heat temperature leaving the HRSG. Therefore, a straight line was achieved for the PP approach evaluation. In contrast, for the AP approach, the results showed that the temperature drops were different between $30 \%, 50 \%$ and $70 \%$. The results of the temperature drop are summarised in Tables 4 and 5. This has been noted from the results on the temperature of exhaust heat leaving the HRSG.

Table 4. Temperature drops at the economiser decrease with increase of PP.

\begin{tabular}{cc}
\hline Pinch Point $(\mathrm{K})$ & Temperature drop $(\mathrm{K})$ \\
\cline { 2 - 2 } & $70 \%, 50 \%$ and $30 \%$ of exhaust heat \\
\hline 10 & 32.16 \\
15 & 31.28 \\
20 & 30.40 \\
25 & 29.52 \\
30 & 28.64 \\
\hline
\end{tabular}




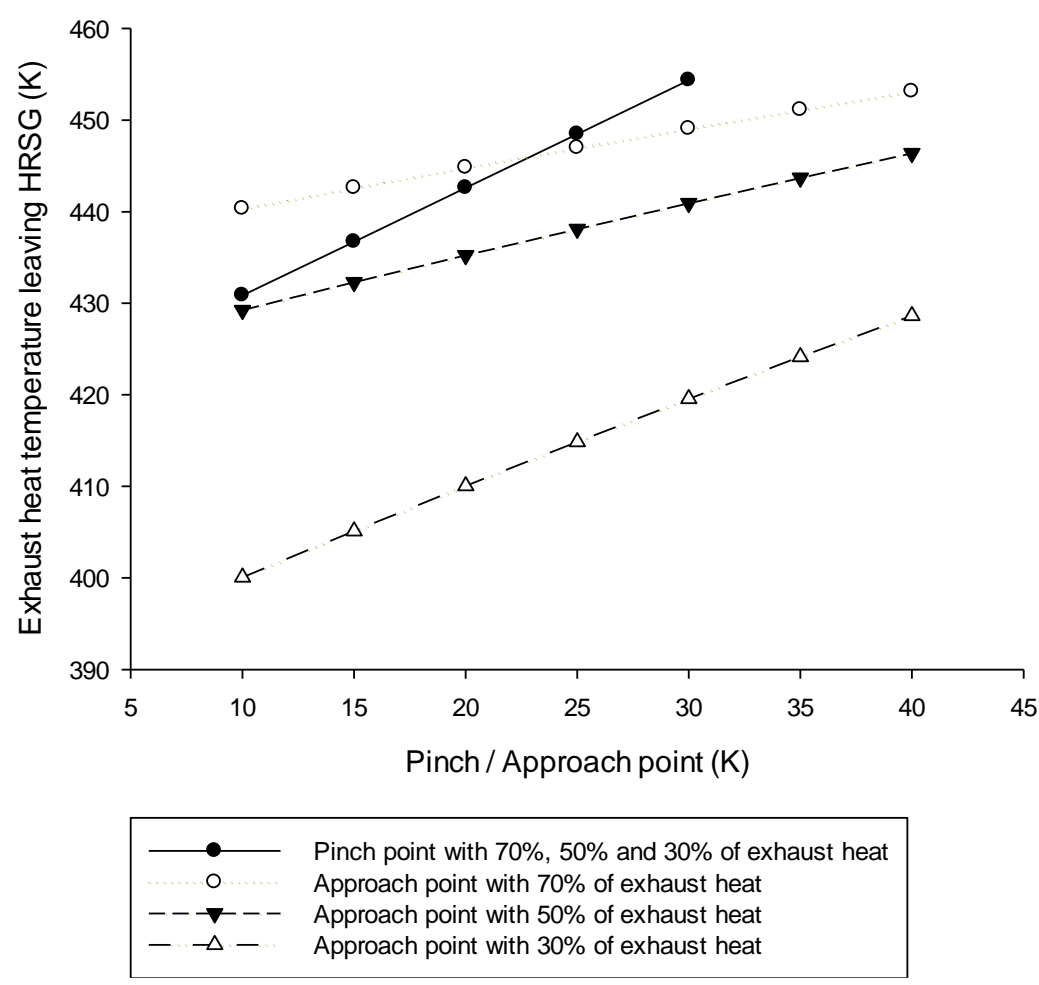

Figure 4. Effect of PP and AP of HRSG on exhaust heat temperatures leaving HRSG.

Table 5. Temperature drops at the economiser decrease with increase of AP for cases $70 \%, 50 \%$ and $30 \%$ of exhaust heat diverted into HRSG.

\begin{tabular}{cccc}
\hline Approach & \multicolumn{3}{c}{ Temperature drop (K) } \\
\cline { 2 - 4 } Point (K) & $70 \%$ of exhaust heat & $50 \%$ of exhaust heat & $30 \%$ of exhaust heat \\
\hline 10 & 32.66 & 43.77 & 72.94 \\
15 & 30.40 & 40.74 & 67.89 \\
20 & 28.19 & 37.78 & 62.96 \\
25 & 26.04 & 34.89 & 58.15 \\
30 & 23.94 & 32.07 & 53.46 \\
35 & 21.88 & 29.32 & 48.86 \\
40 & 19.87 & 26.63 & 44.38 \\
\hline
\end{tabular}

\section{Effect of PP and AP on Efficiency of HRSG}

Figure 5 shows the plot of HRSG efficiencies for cases of different values of PP and AP as per Tables 6 and 7. The plot indicates that as the values of PP and AP increased, the efficiencies of HRSG decreased. The results showed that the maximum efficiency obtained was at $70 \%$ of exhaust heat diverted into HRSG. The range of HRSG performance was about $0.17 \%$ to $0.16 \%$ for the case of $70 \%$ of exhaust heat captured into HRSG and similar results were reported by literature [14]. Hence, the variation in AP had a minimal effect on the efficiency of HRSG. 
Parametric study on effect of pinch and approach points on heat recovery steam generator performance at a district cooling system

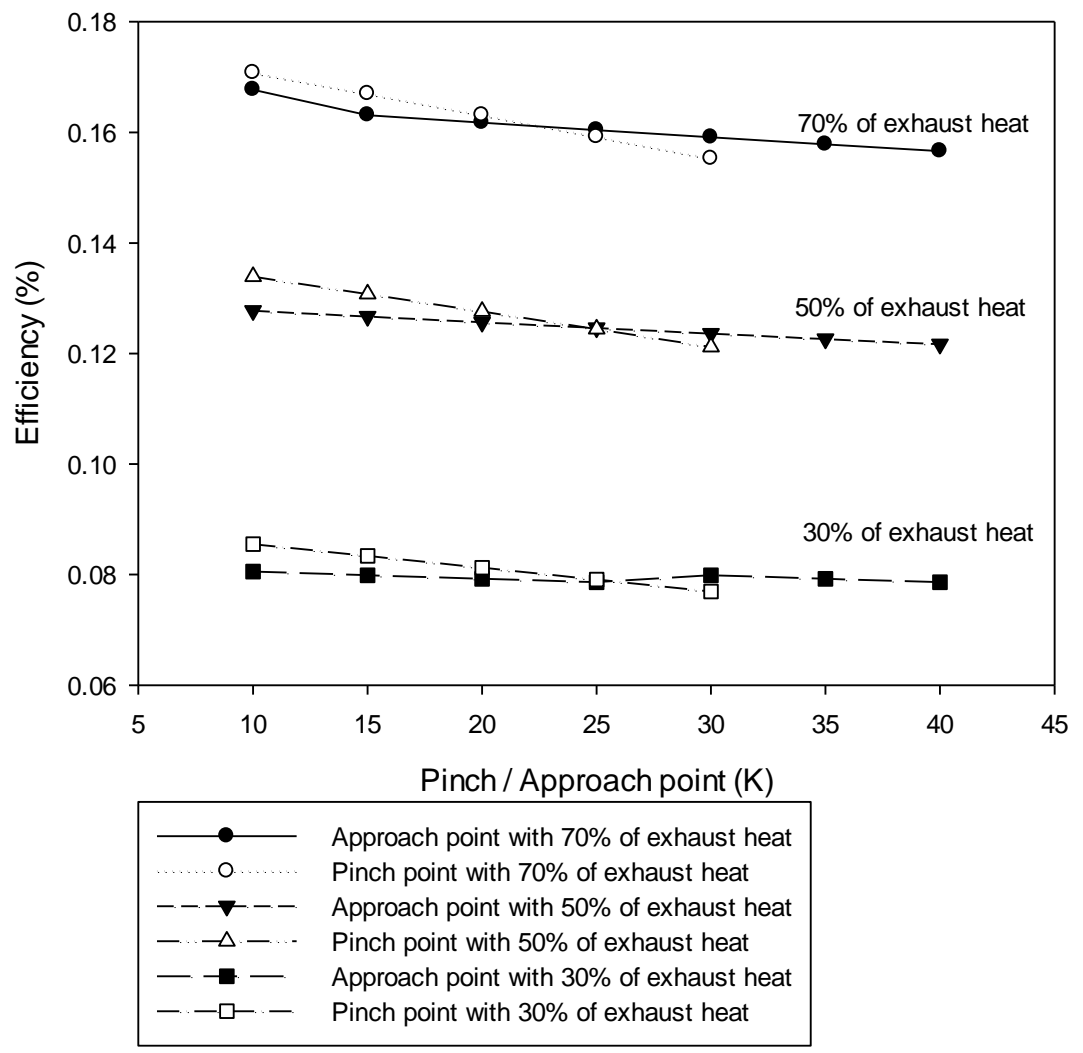

Figure 5. Effect of PP and AP on efficiency of HRSG.

Table 6. Effect of PP on efficiency of HRSG.

\begin{tabular}{ccccc}
\hline PP & AP & \multicolumn{3}{c}{ Efficiency $(\%)$} \\
\cline { 3 - 5 } & $(\mathrm{K})$ & $\begin{array}{c}70 \% \text { of exhaust } \\
\text { heat }\end{array}$ & $\begin{array}{c}50 \% \text { of exhaust } \\
\text { heat }\end{array}$ & $\begin{array}{c}30 \% \text { of exhaust } \\
\text { heat }\end{array}$ \\
\hline 10 & & 0.1708 & 0.1339 & 0.0855 \\
15 & & 0.1670 & 0.1308 & 0.0834 \\
20 & 15 & 0.1631 & 0.1276 & 0.0812 \\
25 & & 0.1592 & 0.1244 & 0.0791 \\
30 & & 0.1553 & 0.1212 & 0.0769 \\
\hline
\end{tabular}

Table 7. Effect of AP on efficiency of HRSG.

\begin{tabular}{|c|c|c|c|c|}
\hline \multirow{2}{*}{$\begin{array}{l}\text { AP } \\
(\mathrm{K})\end{array}$} & \multirow{2}{*}{$\begin{array}{l}\mathrm{PP} \\
(\mathrm{K})\end{array}$} & \multicolumn{3}{|c|}{ Efficiency (\%) } \\
\hline & & $\begin{array}{c}70 \% \text { of exhaust } \\
\text { heat }\end{array}$ & $\begin{array}{c}50 \% \text { of exhaust } \\
\text { heat }\end{array}$ & $\begin{array}{c}30 \% \text { of exhaust } \\
\text { heat }\end{array}$ \\
\hline 10 & & 0.1677 & 0.1278 & 0.0805 \\
\hline 15 & & 0.1631 & 0.1267 & 0.0799 \\
\hline 20 & & 0.1617 & 0.1257 & 0.0792 \\
\hline 25 & 20 & 0.1604 & 0.1246 & 0.0786 \\
\hline 30 & & 0.1591 & 0.1236 & 0.0799 \\
\hline 35 & & 0.1578 & 0.1227 & 0.0792 \\
\hline 40 & & 0.1566 & 0.1217 & 0.0786 \\
\hline
\end{tabular}




\section{Effect of Exhaust Heat Temperature of GT on Mass Flow Rate of Steam}

Figure 6 shows the effect of GT exhaust heat temperature on the mass flow rate of generated steam by HRSG. The results indicated that the mass flow rate of steam increased as the temperature of GT exhaust heat increased. Hence, the exhaust heat temperature from the GT influenced the mass flow rates of steam generated by the HRSG due to more energy input into HRSG. The results and trends on the effect of PP and AP to the mass flow rate of steam generated and the efficiency of HRSG correlate with findings from a published literature by [8].

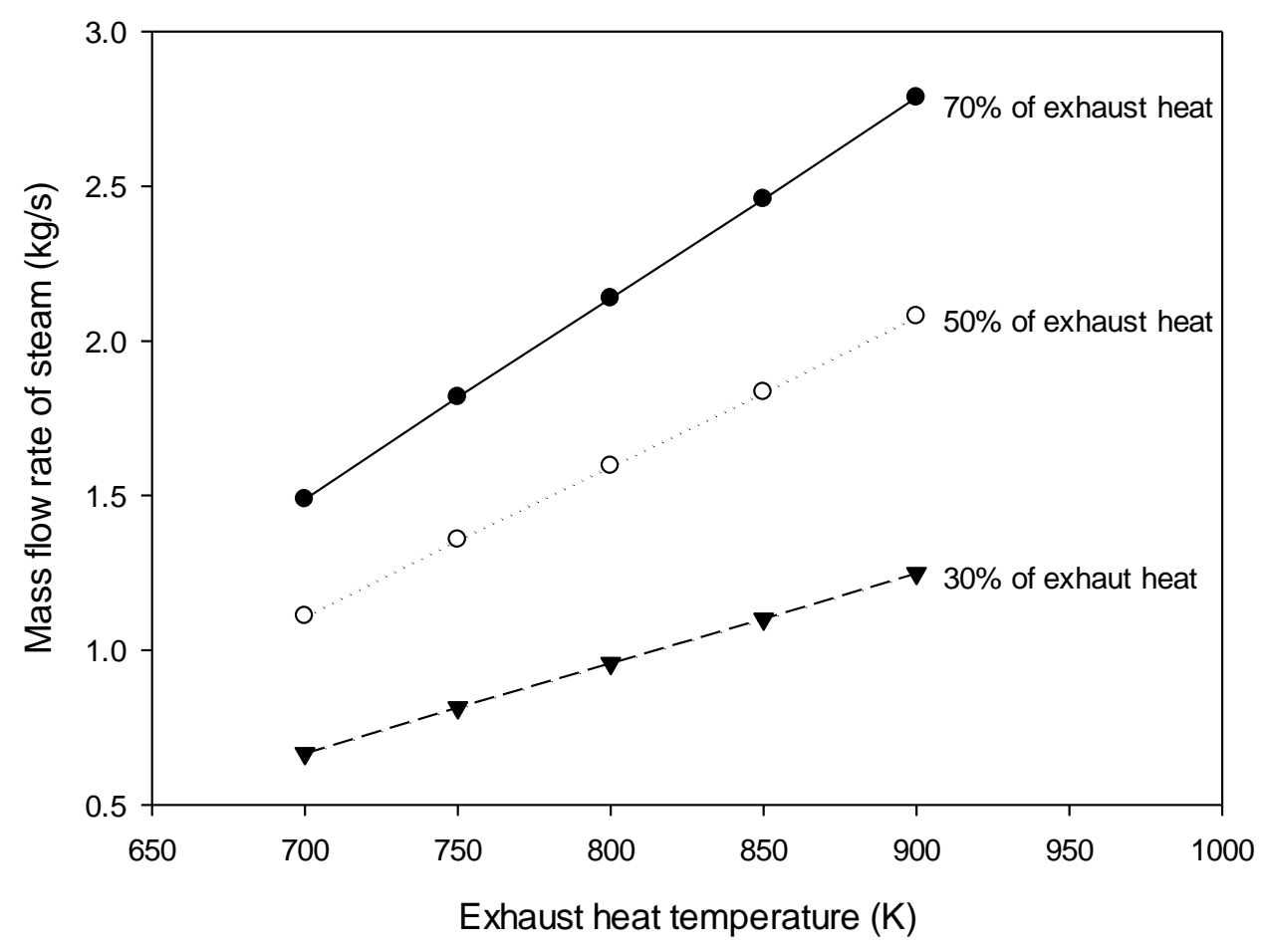

Figure 6. Effect of GT exhaust heat temperature on mass flow rate of steam.

\section{CONCLUSIONS}

Based on the analysis of this study, PP and AP influenced the mass flow rate of steam, exhaust heat temperature leaving HRSG, and efficiency of HRSG. As PP and AP increased, the mass flow rate of steam and efficiency of HRSG decreased. With the increase of PP and AP, the temperature leaving HRSG was increased. The maximum mass flow rate of steam was obtained when $70 \%$ of exhaust heat from GT was diverted into HRSG. When the mass flow rate steam generated was high, the efficiency of HRSG was improved. For this case study, in order to get the optimal mass flow rate of exhaust heat and efficiency of HRSG, the best range of the PP and AP was in between $10 \mathrm{~K}$ to 20 $\mathrm{K}$. This was supported by the literature stating that the positive pinch point was $10 \mathrm{~K}$ to $20 \mathrm{~K}$ for the best heat recovery capacity of HRSG.

\section{ACKNOWLEDGEMENTS}

Authors would like to thank Universiti Teknologi PETRONAS and Ministry of Education for supporting this research study. 


\section{REFERENCES}

[1] Carazas FJG, Salazar CH, Souza GFM. Availability analysis of heat recovery steam generators used in thermal power plants. Energy. 2011;36:3855-70.

[2] Ibrahim TK, Rahman MM. Effects of isentropic efficiency and enhancing strategies on gas turbine performance. Journal of Mechanical Engineering and Sciences. 2013;4:383-96.

[3] Feng H, Zhong W, Wu Y, Tong S. Thermodynamic performance analysis and algorithm model of multi-pressure heat recovery steam generators (hrsg) based on heat exchangers layout. Energy Conversion and Management. 2014;81:282-9.

[4] Zebian H, Mitsos A. A split concept for hrsg (heat recovery steam generators) with simultaneous area reduction and performance improvement. Energy. 2014;71:421-31.

[5] Nadir M, Ghenaiet A. Thermodynamic optimization of several (heat recovery steam generator) hrsg configurations for a range of exhaust gas temperatures. Energy. 2015;86:685-95.

[6] Tyagi K, Khan M. Effect of gas turbine exhaust temperature, stack temperature and ambient temperature on overall efficiency of combine cycle power plant. International Journal of Engineering and Technology. 2010; Vol 2(6):427-9.

[7] Ong'iro A, Ugursal VI, Al Taweel AM, Walker JD. Modeling of heat recovery steam generator performance. Applied Thermal Engineering. 1997;17:427-46.

[8] Butcher CJ, Reddy BV. Second law analysis of a waste heat recovery based power generation system. International Journal of Heat and Mass Transfer. 2007;50:2355-63.

[9] Ganapathy V. Industrial boilers and heat recovery steam generators. New York: Marcel Dekker, Inc.; 2003.

[10] Ahmadi P, Dincer I. Thermodynamic and exergoenvironmental analyses, and multi-objective optimization of a gas turbine power plant. Applied Thermal Engineering. 2011;31:2529-40.

[11] Majid A, Amin M, A Sulaiman S, Ibrahim I, Baharddin Z. Causal model for peak and off peak waste heat recovery for chilled water production. 2012.

[12] Shaharin A, Amin M, Majid A. Gas district cooling in Malaysia. 2011.

[13] UTP GPTD. 2003.

[14] San JY. Second-law performance of heat exchangers for waste heat recovery. Energy. 2010;35:1936-45. 